Ciência Florestal, Santa Maria, v. 27, n. 1, p. 1-19, jan.-mar., 2017

ISSN 0103-9954

\title{
REGENERAÇÃO NATURAL EM DIFERENTES PERÍODOS DE ABANDONO DE ÁREAS APÓS EXTRAÇÃO DE Eucalyptus grandis Hill ex Maiden, EM ARGISSOLO VERMELHO-AMARELO ÁLICO, EM BRUSQUE, SANTA CATARINA
}

\author{
NATURAL REGENERATION IN DIFFERENT PERIODS OF ABANDONMENT OF AREAS AFTER \\ THE EXTRACTION OF Eucalyptus grandis Hill ex Maiden IN RED-YELLOW ULTISOL ÁLIC, \\ IN BRUSQUE, SANTA CATARINA STATE
}

Rafaela Cristina Seubert ${ }^{1}$ João Paulo Maçaneiro ${ }^{2}$ Lauri Amândio Schorn ${ }^{3}$ Deisi Cristine Sebold ${ }^{4}$

\section{RESUMO}

A regeneração natural é considerada uma das técnicas mais adequadas para promover o restabelecimento da vegetação em áreas degradadas. Assim, o presente estudo teve por objetivo avaliar a composição e estrutura dos estratos arbóreo e regenerativo em três áreas sob regeneração natural, caracterizados por diferentes idades após retirada de povoamentos de Eucalyptus grandis. A área de estudo localiza-se na bacia hidrográfica do rio Itajaí, em Brusque - SC. A coleta dos dados foi realizada com a implantação de 56 unidades amostrais (UA) de $200 \mathrm{~m}^{2}$ distribuídas ao longo das margens de um curso d'água em áreas que apresentavam períodos de cinco (AT I), três (AT II) e um e meio (AT III) anos de abandono. Em cada UA foram amostrados os indivíduos vivos com $\mathrm{PAP} \geq 5 \mathrm{~cm}$ e altura maior que $1,3 \mathrm{~m}$. Para o levantamento do estrato regenerativo, foi demarcada uma subunidade de $20 \mathrm{~m}^{2}$ dentro de cada UA do estrato arbóreo, no qual foram amostradas as plantas com altura $\leq 1,30 \mathrm{~m}$. A vegetação estudada apresentou distinções em valores estruturais, evidenciando um dinamismo sucessional no período avaliado. As pioneiras sofreram decréscimo em número de espécies, tanto no estrato arbóreo quanto no regenerativo, enquanto que as espécies clímax tolerantes à sombra apresentaram ingressos com o avanço da idade de abandono das áreas. O número de indivíduos por grupos ecológicos sofreu alterações mais evidentes no estrato regenerativo com o aumento do período de abandono das áreas e as pioneiras diminuíram enquanto que as espécies clímax exigentes em luz aumentaram em densidade.

Palavras-chave: composição; estrutura; restauração; mata ciliar.

\section{ABSTRACT}

Natural regeneration is one of the most appropriate techniques to promote the restoration of vegetation in degraded areas. Thus, this study aimed to evaluate the composition and the structure of the tree and regenerative strata in three areas under natural regeneration, characterized by different ages after the removal of stands of Eucalyptus grandis. The study area is located in the basin of Itajai river in Brusque, SC state. Data collection was performed with the deployment of 56 sample units (AU) of $200 \mathrm{~m}^{2}$ distributed along the banks of a watercourse in areas that had five periods (AT I), three (AT II) and one and a half (AT III) years of abandonment. In each AU, individuals living with PAP $\geq 5 \mathrm{~cm}$ and height greater than $1.3 \mathrm{~m}$ were sampled. To survey the regenerative stratum, it was demarcated a subunit of $20 \mathrm{~m}^{2}$ within each AU of

1 Engenheira Florestal, Mestranda do Programa de Pós-Graduação em Engenharia Florestal, Universidade de Blumenau, Rua São Paulo 3250, Bairro Itoupava Seca, CEP 89030-080, Blumenau (SC), Brasil. rc.seubert@gmail.com

2 Engenheiro Florestal, MSc., Doutorando do Programa de Pós-Graduação em Engenharia Florestal, Universidade Federal do Paraná, Av. Prefeito Lothário Meissner, 900, Jardim Botânico, CEP 80210-170, Curitiba (PR), Brasil. jpmacaneiro@gmail.com

3 Engenheiro Florestal, Dr., Professor de Silvicultura, Universidade Regional de Blumenau, Rua São Paulo, 3250, Bairro Itoupava Seca, CEP 89030-080, Blumenau (SC), Brasil. Lauri.schorn@gmail.com

4 Engenheira Florestal, Rua São Paulo, 3250, Bairro Itoupava Seca, CEP 89030-080, Blumenau (SC), Brasil. deisi.iffsc@gmail.com

Recebido para publicação em 4/02/2012 e aceito em 27/05/2015

Ci. Fl., v. 27, n. 1, jan.-mar., 2017 
tree communities where the plants were sampled with height $\leq 1,30 \mathrm{~m}$. The studied vegetation presented distinctions in structural values, showing a succession dynamics during the study period. The pioneering suffered decrease in number of species, both in the tree layer as the regenerative, while shade-tolerant climax species had recruitments along with the advancement of the age of abandoned areas. The number of plants for ecological groups showed more pronounced changes in the regeneration layer with the increased abandonment period of areas and pioneer species decreased while the demanding climax light increased in density.

Keyword: composition; structure; restoration; riparian vegetation.

\section{INTRODUÇÃO}

No Brasil, a eliminação das matas ciliares tem causado aumento significativo nos processos de erosão dos solos, com prejuízo à hidrologia regional, evidente redução da biodiversidade e a degradação de extensas áreas submetidas a estas ações antrópicas (BARBOSA, 2000).

As florestas ciliares são fortemente influenciadas por uma série de fatores físicos locais, como as variações edáficas e topográficas, além dos processos de perturbações naturais e antrópicos que são muito frequentes nessas comunidades (OLIVEIRA-FILHO et al., 1994b; NEBEL et al., 2001; CAMPOS; SOUZA, 2002). As florestas ciliares são consideradas como áreas de proteção permanente no Brasil (CARDOSO-LEITE et al., 2004; FERREIRA; DIAS, 2004) e protegidas pela Lei $\mathrm{n}^{\mathrm{o}} 12.651$ de 2012. De um modo geral, essas florestas estão inseridas no fundo dos vales e correspondem às áreas de uma bacia hidrográfica na qual, comumente, ocorrem os solos mais férteis e úmidos. Assim, as matas ciliares são tão propensas a derrubadas, dando espaço a outros usos agrícolas ou silviculturais (BOTELHO; DAVIDE, 2002; OLIVEIRA-FILHO et al., 1994b).

Os plantios florestais implantados no Brasil em décadas passadas abrangeram muitas áreas consideradas como de preservação permanente. Essas áreas incluem margens de nascentes e de cursos d'água, topos de morro e áreas com inclinação superior a $45^{\circ}$, entre outras. Por ocasião da rotação desses povoamentos implantados e em atendimento às determinações legais, os proprietários necessitam realizar a restauração da vegetação natural dessas áreas.

A regeneração natural é considerada uma das técnicas mais econômicas para restauração de ecossistemas degradados (SEITZ, 1994; NAPPO et al., 1999). Alvarenga et al. (2006), por exemplo, apontam a regeneração natural como uma das alternativas mais promissoras para a recomposição da vegetação ciliar em função dos aspectos ecológicos, silviculturais e econômicos. Além disso, para que o processo de sucessão florestal se desenvolva é necessário analisar alguns pressupostos, de acordo com Rodrigues e Gandolfi (2000): a) existência de área aberta, na qual espécies vegetais possam se estabelecer e sobreviver; b) o ingresso de espécies ao longo do tempo, ou que sementes preexistentes no solo germinem introduzindo novas espécies nessa área e; c) presença de espécies com comportamentos ecológicos distintos, promovendo uma gradual substituição na área, aspecto que caracteriza a sucessão.

A preocupação com a conservação e a restauração da cobertura florestal ao longo dos rios é relativamente recente no Brasil e tem sido objeto de discussões amplas e frequentes, abordando aspectos técnicos, científicos, conservacionistas e da legislação correlata (DURIGAN; SILVEIRA, 1999). Com isso, estudos florísticos e fitossociológicos são importantes, pois contribuem para o conhecimento preliminar das florestas ciliares, fornecendo informações básicas para a execução de projetos mais detalhados sobre a vegetação e são primordiais no planejamento de ações de preservação e conservação da diversidade local (OLIVEIRA-FILHO; FONTES, 2000), além das ações de recuperação ou restauração.

Diante do exposto, esse trabalho teve como objetivo avaliar as diferenças entre a composição e estrutura da regeneração natural em áreas consideradas como de preservação permanente, com três diferentes períodos de abandono após a retirada de povoamentos de Eucalyptus grandis Hill ex Maiden, em Brusque - SC.

\section{MATERIAL E MÉTODOS}

As áreas estudadas estão inseridas na bacia hidrográfica do rio Itajaí, sub-bacia do rio Itajaí- 
Mirim, em Brusque - SC. Situam-se em uma fazenda utilizada para plantios de Eucalyptus grandis

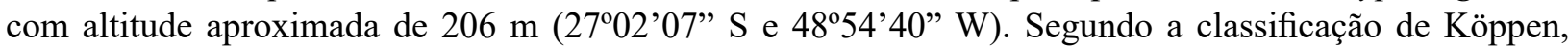
o município de Brusque apresenta clima do tipo Cfa - Clima subtropical mesotérmico úmido com verão quente. Sua temperatura média anual varia entre $18-20^{\circ} \mathrm{C}$, com precipitação total anual de 1700 a 1900 $\mathrm{mm}$ bem distribuídos durante o ano e a umidade relativa anual entre $84-86 \%$ (EMPRESA DE PESQUISA AGROPECUÁRIA E EXTENSÃO RURAL DE SANTA CATARINA, 2002).

A geologia da região é formada pelo Complexo Metamórfico Brusque, que é composto principalmente pela Formação Botuverá (filitos e xistos), pelo Granodiorito Valsungana e pelo Granito Guabiruba (EMBRAPA, 1998). O relevo varia de ondulado a forte ondulado nas encostas, e suave ondulado nas depressões e fundos de vales. Predomina, na área de estudo, o Argissolo Vermelho-Amarelo álico de textura média argilosa (EMBRAPA, 2004).

A vegetação da área de estudo está inserida na região fitoecológica Floresta Ombrófila Densa Submontana (IBGE, 2012). Essa formação tem como principais características árvores bem desenvolvidas podendo alcançar até $35 \mathrm{~m}$ de altura e estabelecidas sobre solos bem drenados e de boa fertilidade, com grande quantidade de epífitos fixados sobre as copas das árvores (SEVEGNANI, 2002).

Com objetivo de conhecer a composição e estrutura da regeneração natural em distintas idades de abandono de área, o levantamento foi realizado em três talhões situados em margens de cursos de água, caracterizados por diferentes períodos de abandono após a retirada de povoamentos com Eucalyptus grandis: Ambiente I (AT I) com cinco anos de regeneração, ambiente II (AT II) com três anos de regeneração e ambiente III (AT III) com um ano e meio de regeneração. O povoamento anteriormente extraído apresentava idade de nove anos e foi implantado, conduzido e explorado através de operações não mecanizadas. A exploração realizada foi somente de corte raso, sem desbastes. Não houve aplicação de herbicidas durante o ciclo de ocupação da área com o povoamento de Eucalyptus grandis.

Nos três talhões estudados, a avalição fitossociológica do estrato arbóreo foi realizada a partir de unidades amostrais (UA) de $200 \mathrm{~m}^{2}(20 \times 10 \mathrm{~m})$ demarcadas paralelamente ao principal curso d'água existente e assim distribuídas: 19 UA no AT I, 21 UA no AT II e 16 UA no AT III. Foi utilizado número diferente de unidades amostrais nos talhões visando atender à mesma proporcionalidade amostral nas três áreas, que apresentavam 4,75, 5,25 e 4,0 hectares, respectivamente em AT I, AT II e AT III. As unidades amostrais foram locadas de forma sistemática, distanciadas entre si por $20 \mathrm{~m}$ e a uma distância média de $15 \mathrm{~m}$ do início do leito do curso d'água. Em cada UA foram amostrados os indivíduos arbóreos com PAP $\geq$ $5 \mathrm{~cm}$ e altura superior a $1,3 \mathrm{~m}$. Para avaliação fitossociológica do estrato regenerativo, foi demarcada uma subunidade de $20 \mathrm{~m}^{2}(10 \times 2 \mathrm{~m})$ dentro de cada UA do estrato arbóreo, na qual foram amostradas as espécies arbóreas e arbustivas com altura igual ou inferior a 1,30 m.

O material botânico coletado foi identificado pela comparação com exsicatas existentes no Herbário do Laboratório de Dendrologia da Universidade Regional de Blumenau (FURB), consulta à literatura taxonômica e aos especialistas da FURB. As espécies foram agrupadas em famílias, de acordo com o sistema do Angiosperm Phylogeny Group III (2009).

As espécies foram classificadas segundo sua síndrome de dispersão (PIJL, 1982; MORELLATO et al., 1989; NAPPO et al., 2004) e por grupo ecológico, adotando-se a metodologia sugerida por OliveiraFilho (1994a) nas seguintes categorias: pioneiras (P), clímax exigentes de luz (CL) e clímax tolerantes à sombra (CS).

Para descrever a estrutura da vegetação do estrato arbóreo e regenerativo foram calculados, para cada espécie, os parâmetros fitossociológicos clássicos de Mueller-Dombois e Ellenberg (2002), ou seja, densidade e frequência absolutas.

Para estimar a diversidade de espécies ocorrente entre os ambientes foram utilizados os índices de diversidade de Shannon (H', logaritmo neperiano) e o índice de equabilidade de Pielou (J'), descritos por Magurran (2004).

\section{RESULTADOS E DISCUSSÃO}

Nos três ambientes foram amostrados 3.137 indivíduos distribuídos em 141 espécies, 91 gêneros e 40 famílias. Nas unidades amostrais do estrato arbóreo (A) foram amostrados 2.359 indivíduos distribuídos 
em 131 espécies e 38 famílias, resultando em uma densidade total de 2.106 ind.ha $^{-1}$. Nas subunidades do estrato regenerativo (R) foram amostrados 778 indivíduos distribuídos em 79 espécies e 29 famílias, resultando em uma densidade total de 6.946 ind.ha $^{-1}$.

No AT I ocorreu o maior número de espécies (101) quando comparado com o AT II (95) e AT III (79) respectivamente, apresentando ainda um número de indivíduos superior no estrato arbóreo e no estrato regenerativo (Tabela 1).

TABELA 1: Espécies arbóreo-arbustivas registradas nos três ambientes em abandono após a extração de Eucalyptus grandis Hill ex Maiden em Brusque - SC. As espécies presentes nos estratos arbóreo (A) e regenerativo (R) dos ambientes I (AT I), II (AT II) e III (AT III) respectivamente, encontram-se acompanhadas de sua família, nome científico, síndrome de dispersão (SD): Anemo $=$ anemocórica, Auto $=$ autocórica, Zoo = zoocórica; e grupo ecológico (GE): Pioneiras (P), clímax exigente em luz (CL) e clímax tolerante à sombra (CS).

TABLE 1: Tree species recorded in the three environments that have been abandoned after the extraction of Eucalyptus grandis Hill ex Maiden in Brusque, SC state. The species present in the upper stratum (A) and regenerative (R) environments I (AT I), II (AT II) and III (AT III) respectively, are accompanied by family, scientific name, type of dispersal (SD): Anemo = anemocoric, Auto $=$ autochory, Zoo = zoochoric; and environmental group $(\mathrm{EG})$ : Pioneer $(\mathrm{P})$, climax light demanding (CL) and shade-tolerant (CS).

\begin{tabular}{|c|c|c|c|c|c|c|}
\hline Família & Espécie & AT I & AT II & AT III & GE & SD \\
\hline \multirow{5}{*}{ Annonaceae } & Annona cacans Warm. & A & $\mathrm{AR}$ & & $\mathrm{CL}$ & Zoo \\
\hline & Annona neosericea H.Rainer & A & & & $\mathrm{CL}$ & Zoo \\
\hline & Annona sylvatica A.St.-Hil. & AR & & & $\mathrm{CL}$ & Zoo \\
\hline & Guatteria australis A.St.-Hil. & & $\mathrm{AR}$ & A & $\mathrm{CS}$ & Zoo \\
\hline & Xylopia brasiliensis Spreng. & A & A & AR & $\mathrm{CL}$ & Zoo \\
\hline \multirow{2}{*}{ Apocynaceae } & Aspidosperma australe Müll.Arg. & A & & & $\mathrm{CL}$ & Anemo \\
\hline & Tabernaemontana catharinensis A.DC. & AR & $\mathrm{R}$ & A & CL & Zoo \\
\hline \multirow{3}{*}{ Aquifoliaceae } & Ilex brevicuspis Reissek & A & & & $\mathrm{CS}$ & Zoo \\
\hline & Ilex dumosa Reissek & A & A & A & $\mathrm{CL}$ & Zoo \\
\hline & Ilex theezans Mart. ex Reissek & & A & & $\mathrm{CL}$ & Zoo \\
\hline Araliaceae & Schefflera morototoni (Aubl.) Maguire et al. & & A & & $\mathrm{CL}$ & Zoo \\
\hline \multirow{3}{*}{ Arecaceae } & Bactris setosa Mart. & & $\mathrm{R}$ & & $\mathrm{CS}$ & Zoo \\
\hline & Euterpe edulis Mart. & AR & & A & $\mathrm{CS}$ & Zoo \\
\hline & Syagrus romanzoffiana (Cham.) Glassman & & & A & $\mathrm{CL}$ & Zoo \\
\hline \multirow{12}{*}{ Asteraceae } & Austroeupatorium inulaefolium (Kunth) R.M.King \& H.Rob. & & & A & $\mathrm{P}$ & Anemo \\
\hline & Baccharis dracunculifolia DC. & A & & A & $\mathrm{P}$ & Anemo \\
\hline & Baccharis microdonta DC. & & & AR & $\mathrm{P}$ & Anemo \\
\hline & Baccharis punctulata DC. & & A & & $\mathrm{P}$ & Anemo \\
\hline & Baccharis semiserrata DC. & A & A & AR & $\mathrm{P}$ & Anemo \\
\hline & Piptocarpha axillaris (Less.) Baker & A & A & & $\mathrm{P}$ & Anemo \\
\hline & Symphyopappus casarettoi B.L.Rob. & & A & A & $\mathrm{P}$ & Anemo \\
\hline & Symphyopappus compressus (Gardner) B.L.Rob. & A & AR & AR & $\mathrm{P}$ & Anemo \\
\hline & Vernonanthura discolor (Spreng.) H.Rob. & A & A & & $\mathrm{P}$ & Anemo \\
\hline & Vernonanthura divaricata (Spreng.) H.Rob. & A & A & A & $\mathrm{P}$ & Anemo \\
\hline & Vernonanthura puberula (Less.) H.Rob. & A & AR & $\mathrm{AR}$ & $\mathrm{P}$ & Anemo \\
\hline & Vernonanthura tweediana (Baker) H.Rob. & & A & A & $\mathrm{P}$ & Anemo \\
\hline Bignoniaceae & Jacaranda puberula Cham. & A & AR & $\mathrm{AR}$ & CL & Anemo \\
\hline
\end{tabular}

Continua... 
TABELA 1: Continuação...

TABLE 1: Continued...

\begin{tabular}{|c|c|c|c|c|c|c|}
\hline Família & Espécie & AT I & AT II & AT III & GE & SD \\
\hline Boraginaceae & Cordia silvestris Fresen. & A & & & $\mathrm{CL}$ & Zoo \\
\hline Cannabaceae & Trema micrantha (L.) Blume & A & AR & A & $\mathrm{P}$ & Zoo \\
\hline Celastraceae & Maytenus robusta Reissek & $\mathrm{R}$ & & $\mathrm{R}$ & $\mathrm{CS}$ & Zoo \\
\hline Chloranthaceae & Hedyosmum brasiliense Miq. & $\mathrm{AR}$ & AR & AR & $\mathrm{CL}$ & Zoo \\
\hline Clethraceae & Clethra scabra Pers. & A & A & & $\mathrm{CL}$ & Auto \\
\hline Elaocarpaceae & Sloanea guianensis (Aubl.) Benth. & A & A & $\mathrm{R}$ & $\mathrm{CS}$ & Zoo \\
\hline \multirow{4}{*}{ Euphorbiaceae } & Alchornea glandulosa Poepp. \& Endl. & A & $\mathrm{AR}$ & $\mathrm{AR}$ & $\mathrm{P}$ & Zoo \\
\hline & Alchornea triplinervia (Spreng.) Müll.Arg. & A & $\mathrm{AR}$ & & $\mathrm{CL}$ & Zoo \\
\hline & Sapium glandulosum (L.) Morong & A & A & & $\mathrm{CL}$ & Zoo \\
\hline & Tetrorchidium rubrivenium Poepp. & A & & & $\mathrm{CS}$ & Zoo \\
\hline \multirow{17}{*}{ Fabaceae } & Abarema langsdorffii (Benth.) Barneby \& J.W.Grimes & & A & A & CL & Zoo \\
\hline & Andira fraxinifolia Benth. & A & & & $\mathrm{CL}$ & Zoo \\
\hline & Dahlstedtia pentaphylla (Taub.) Burkart & A & & & CL & Auto \\
\hline & Dalbergia brasiliensis Vogel & & $\mathrm{AR}$ & & $\mathrm{CL}$ & Anemo \\
\hline & Dalbergia frutescens (Vell.) Britton & & AR & & $\mathrm{CL}$ & Anemo \\
\hline & Enterolobium contortisiliquum (Vell.) Morong & & & A & $\mathrm{CL}$ & Auto \\
\hline & Inga marginata Willd. & A & A & & $\mathrm{CL}$ & Zoo \\
\hline & Lonchocarpus campestris Mart. ex Benth. & & A & & $\mathrm{CL}$ & Anemo \\
\hline & Lonchocarpus guillemineanus (Tul.) Malme & & & A & CL & Anemo \\
\hline & Machaerium hirtum (Vell.) Stellfeld & A & AR & $\mathrm{R}$ & $\mathrm{CL}$ & Anemo \\
\hline & Mimosa bimucronata (DC.) Kuntze & A & $\mathrm{AR}$ & $\mathrm{AR}$ & $\mathrm{P}$ & Anemo \\
\hline & Mimosa scabrella Benth. & & & A & $P$ & Anemo \\
\hline & Piptadenia gonoacantha (Mart.) J.F.Macbr. & A & & & $\mathrm{P}$ & Anemo \\
\hline & Platymiscium floribundum Vogel & & A & & $\mathrm{CL}$ & Anemo \\
\hline & Schizolobium parahyba (Vell.) Blake & A & & & $\mathrm{P}$ & Auto \\
\hline & Senna macranthera (DC. ex Collad.) H.S.Irwin \& Barneby & A & & A & $\mathrm{P}$ & Auto \\
\hline & Zollernia ilicifolia (Brongn.) Vogel & A & A & $\mathrm{R}$ & $\mathrm{CS}$ & Zoo \\
\hline \multirow{3}{*}{ Lamiaceae } & Aegiphila integrifolia (Jacq.) Moldenke & A & A & & $\mathrm{P}$ & Zoo \\
\hline & Aegiphila obducta Vell. & A & A & & $\mathrm{P}$ & Zoo \\
\hline & Vitex megapotamica (Spreng.) Moldenke & & A & & $\mathrm{CL}$ & Zoo \\
\hline \multirow{8}{*}{ Lauraceae } & Aniba firmula (Nees \& Mart.) Mez & & $\mathrm{R}$ & A & $\mathrm{CS}$ & Zoo \\
\hline & Cryptocarya moschata Nees \& Mart. & & A & & $\mathrm{CS}$ & Zoo \\
\hline & Endlicheria paniculata (Spreng.) J.F.Macbr & $\mathrm{AR}$ & A & A & $\mathrm{CS}$ & Zoo \\
\hline & Nectandra cuspidata Nees & $\mathrm{AR}$ & $\mathrm{AR}$ & $\mathrm{AR}$ & $\mathrm{CL}$ & Zoo \\
\hline & Nectandra grandiflora Nees & & & A & $\mathrm{CL}$ & Zoo \\
\hline & Nectandra oppositifolia Nees & $\mathrm{AR}$ & A & AR & $\mathrm{CL}$ & Zoo \\
\hline & Nectandra puberula (Schott) Nees & & & A & $\mathrm{CL}$ & Zoo \\
\hline & Ocotea puberula (Rich.) Nees & A & $\mathrm{AR}$ & $\mathrm{AR}$ & $\mathrm{CL}$ & Zoo \\
\hline Magnoliaceae & Magnolia ovata (A.St.-Hil.) Spreng. & A & A & A & $\mathrm{CS}$ & Zoo \\
\hline Malpighiaceae & Bunchosia maritima (Vell.) J.F.Macbr. & A & & $\mathrm{R}$ & $\mathrm{CS}$ & Zoo \\
\hline Malvaceae & Pseudobombax grandiflorum (Cav.) A.Robyns & A & & & $\mathrm{CL}$ & Anemo \\
\hline
\end{tabular}

Continua... 
TABELA 1: Continuação...

TABLE 1: Continued...

\begin{tabular}{|c|c|c|c|c|c|c|}
\hline Família & Espécie & AT I & AT II & AT III & GE & SD \\
\hline \multirow{9}{*}{ Melastomataceae } & Leandra dasytricha (A.Gray) Cogn. & $\mathrm{AR}$ & & & $\mathrm{CL}$ & Zoo \\
\hline & Leandra regnellii (Triana) Cogn. & $\mathrm{AR}$ & $\mathrm{R}$ & & $\mathrm{CL}$ & Zoo \\
\hline & Miconia cabucu Hoehne & A & $\mathrm{AR}$ & & $\mathrm{CL}$ & Zoo \\
\hline & Miconia cinnamomifolia (DC.) Naudin & A & $\mathrm{AR}$ & $\mathrm{R}$ & $\mathrm{P}$ & Zoo \\
\hline & Miconia latecrenata (DC.) Naudin & $\mathrm{AR}$ & $\mathrm{R}$ & & $\mathrm{CL}$ & Zoo \\
\hline & Miconia valtheri Naudin & A & A & & $\mathrm{CL}$ & Zoo \\
\hline & Tibouchina pilosa Cogn. & $\mathrm{AR}$ & AR & $\mathrm{AR}$ & $\mathrm{P}$ & Anemo \\
\hline & Tibouchina pulchra Cogn. & & A & & $\mathrm{CL}$ & Anemo \\
\hline & Tibouchina urvilleana (DC.) Cogn. & $\mathrm{AR}$ & AR & $\mathrm{AR}$ & $\mathrm{P}$ & Anemo \\
\hline \multirow{4}{*}{ Meliaceae } & Cabralea canjerana (Vell.) Mart. & $\mathrm{AR}$ & $\mathrm{R}$ & & $\mathrm{CS}$ & Zoo \\
\hline & Cedrela fissilis Vell. & $\mathrm{A}$ & & & $\mathrm{CL}$ & Anemo \\
\hline & Guarea macrophylla Vahl & $\mathrm{AR}$ & A & $\mathrm{AR}$ & CS & Zoo \\
\hline & Trichilia lepidota Mart. & A & A & $\mathrm{R}$ & $\mathrm{CS}$ & Zoo \\
\hline \multirow{2}{*}{ Monimiaceae } & Mollinedia schottiana (Spreng.) Perkins & A & A & A & $\mathrm{CS}$ & Zoo \\
\hline & Mollinedia triflora (Spreng.) Tul. & $\mathrm{R}$ & $\mathrm{R}$ & $\mathrm{AR}$ & $\mathrm{CS}$ & Zoo \\
\hline \multirow{4}{*}{ Moraceae } & Brosimum lactescens (S.Moore) C.C.Berg & A & & & $\mathrm{CL}$ & Zoo \\
\hline & Ficus adhatodifolia Schott ex Spreng. & A & $\mathrm{AR}$ & A & $\mathrm{CS}$ & Zoo \\
\hline & Ficus cestrifolia Schott ex Spreng. & A & & & $\mathrm{CS}$ & Zoo \\
\hline & Sorocea bonplandii (Baill.) W.C.Burger et al. & A & & & $\mathrm{CS}$ & Zoo \\
\hline Myristicaceae & Virola bicuhyba (Schott ex Spreng.) Warb. & $\mathrm{R}$ & $\mathrm{R}$ & & $\mathrm{CL}$ & Zoo \\
\hline \multirow[b]{2}{*}{ Myrsinaceae } & Myrsine coriacea (Sw.) R.Br. ex Roem. \& Schult. & $\mathrm{AR}$ & $\mathrm{AR}$ & $\mathrm{AR}$ & $\mathrm{P}$ & Zoo \\
\hline & $\begin{array}{l}\text { Myrsine hermogenesii (Jung-Mend. \& Bernacci) M.F.Freitas } \\
\text { \& Kin.-Gouv. }\end{array}$ & & & $\mathrm{R}$ & $\mathrm{CL}$ & Zoo \\
\hline \multirow{12}{*}{ Myrtaceae } & Calyptranthes lucida Mart. ex DC. & & A & & $\mathrm{CL}$ & Zoo \\
\hline & Campomanesia reitziana D.Legrand & $\mathrm{AR}$ & $\mathrm{AR}$ & $\mathrm{R}$ & $\mathrm{CS}$ & Zoo \\
\hline & Eugenia brasiliensis Lam. & A & & & $\mathrm{CS}$ & Zoo \\
\hline & Eugenia catharinensis D.Legrand & & $\mathrm{R}$ & & $\mathrm{CS}$ & Zoo \\
\hline & Eugenia kleinii D.Legrand & A & $\mathrm{R}$ & $\mathrm{R}$ & $\mathrm{CS}$ & Zoo \\
\hline & Myrceugenia myrcioides (Cambess.) O.Berg & $\mathrm{AR}$ & & & $\mathrm{CS}$ & Zoo \\
\hline & Myrcia hebepetala DC. & & AR & $\mathrm{AR}$ & $\mathrm{CS}$ & Zoo \\
\hline & Myrcia pubipetala Miq. & & & $\mathrm{AR}$ & CL & Zoo \\
\hline & Myrcia spectabilis DC. & A & & & $\mathrm{CS}$ & Zoo \\
\hline & Myrcia splendens (Sw.) DC. & A & $\mathrm{AR}$ & $\mathrm{AR}$ & $\mathrm{CL}$ & Zoo \\
\hline & Psidium cattleianum Sabine & A & AR & $\mathrm{R}$ & $\mathrm{CL}$ & Zoo \\
\hline & Psidium guajava L. & A & $\mathrm{R}$ & $\mathrm{AR}$ & $\mathrm{CL}$ & Zoo \\
\hline Nyctaginaceae & Guapira opposita (Vell.) Reitz & A & $\mathrm{R}$ & & $\mathrm{CS}$ & Zoo \\
\hline Peraceae & Pera glabrata (Schott) Poepp. ex Baill. & A & A & A & $\mathrm{CL}$ & Zoo \\
\hline Phyllanthaceae & Hieronyma alchorneoides Allemão & $\mathrm{AR}$ & $\mathrm{AR}$ & A & $\mathrm{CL}$ & Zoo \\
\hline
\end{tabular}

Continua... 
TABELA 1: Continuação...

TABLE 1: Continued...

\begin{tabular}{|c|c|c|c|c|c|c|}
\hline Família & Espécie & AT I & AT II & AT III & GE & SD \\
\hline \multirow{7}{*}{ Piperaceae } & Piper aduncum L. & $\mathrm{AR}$ & $\mathrm{AR}$ & $\mathrm{AR}$ & $\mathrm{P}$ & Zoo \\
\hline & Piper arboreum Aubl. & $\mathrm{AR}$ & $\mathrm{AR}$ & $\mathrm{AR}$ & $\mathrm{CS}$ & Zoo \\
\hline & Piper cernuum Vell. & A & & $\mathrm{R}$ & $\mathrm{CS}$ & Zoo \\
\hline & Piper crassinervium Kunth & A & $\mathrm{R}$ & & $\mathrm{CS}$ & Zoo \\
\hline & Piper hispidinervum C.DC. & A & & & $\mathrm{CS}$ & Zoo \\
\hline & Piper lindbergii C.DC. & $\mathrm{R}$ & $\mathrm{AR}$ & $\mathrm{AR}$ & $\mathrm{CS}$ & Zoo \\
\hline & Piper solmsianum C.DC. & $\mathrm{R}$ & & & $\mathrm{CS}$ & Zoo \\
\hline Proteaceae & Roupala brasiliensis Klotzsch & & & A & $\mathrm{CL}$ & Anemo \\
\hline \multirow{11}{*}{ Rubiaceae } & Amaioua guianensis Aubl. & & $\mathrm{A}$ & & $\mathrm{CS}$ & Zoo \\
\hline & Bathysa australis (A.St.-Hil.) K.Schum. & $\mathrm{AR}$ & $\mathrm{AR}$ & & $\mathrm{CS}$ & Auto \\
\hline & Coussarea contracta (Walp.) Müll.Arg. & A & & & $\mathrm{CS}$ & Zoo \\
\hline & Margaritopsis astrellantha (Wernham) L.Andersson & $\mathrm{R}$ & & & $\mathrm{CS}$ & Zoo \\
\hline & Posoqueria latifolia (Rudge) Schult. & & $\mathrm{R}$ & & $\mathrm{CS}$ & Zoo \\
\hline & Psychotria carthagenensis Jacq. & & A & & $\mathrm{CL}$ & Zoo \\
\hline & Psychotria nuda (Cham. \& Schltdl.) Wawra & $\mathrm{R}$ & & & $\mathrm{CS}$ & Zoo \\
\hline & Psychotria officinalis (Aubl.) Raeusch. ex Sandwith & $\mathrm{R}$ & $\mathrm{R}$ & $\mathrm{R}$ & $\mathrm{CS}$ & Zoo \\
\hline & Psychotria suterella Müll.Arg. & $\mathrm{AR}$ & $\mathrm{R}$ & $\mathrm{R}$ & $\mathrm{CS}$ & Zoo \\
\hline & Psychotria vellosiana Benth. & A & A & $\mathrm{R}$ & $\mathrm{CL}$ & Zoo \\
\hline & Rudgea recurva Müll.Arg. & & $\mathrm{R}$ & & $\mathrm{CS}$ & Zoo \\
\hline \multirow{2}{*}{ Rutaceae } & Esenbeckia grandiflora Mart. & $\mathrm{R}$ & & $\mathrm{R}$ & CS & Auto \\
\hline & Zanthoxylum rhoifolium Lam. & $\mathrm{A}$ & A & $\mathrm{A}$ & $\mathrm{CL}$ & Zoo \\
\hline \multirow{3}{*}{ Salicaceae } & Casearia decandra Jacq. & A & A & A & $\mathrm{P}$ & Zoo \\
\hline & Casearia sylvestris $\mathrm{Sw}$. & $\mathrm{AR}$ & $\mathrm{AR}$ & AR & $\mathrm{P}$ & Zoo \\
\hline & Xylosma prockia (Turcz.) Turcz. & & & $\mathrm{R}$ & $\mathrm{CL}$ & Zoo \\
\hline \multirow{2}{*}{ Sapindaceae } & Cupania vernalis Cambess. & A & $\mathrm{AR}$ & $\mathrm{AR}$ & CL & Zoo \\
\hline & Matayba intermedia Radlk. & $\mathrm{AR}$ & $\mathrm{AR}$ & $\mathrm{R}$ & $\mathrm{CL}$ & Zoo \\
\hline Sapotaceae & Chrysophyllum inornatum Mart. & & $\mathrm{A}$ & & $\mathrm{CL}$ & Zoo \\
\hline \multirow{6}{*}{ Solanaceae } & Solanum caeruleum Vell. & & A & & $\mathrm{P}$ & Zoo \\
\hline & Solanum guaraniticum A.St.-Hil. & A & $\mathrm{AR}$ & A & $\mathrm{P}$ & Zoo \\
\hline & Solanum mauritianum Scop. & $\mathrm{R}$ & & $\mathrm{R}$ & $\mathrm{P}$ & Zoo \\
\hline & Solanum paniculatum L. & & & A & $\mathrm{P}$ & Zoo \\
\hline & Solanum pseudoquina A.St.-Hil. & A & A & A & $\mathrm{P}$ & Zoo \\
\hline & Solanum sanctae-catharinae Dunal & & & $\mathrm{AR}$ & $\mathrm{P}$ & Zoo \\
\hline Symplocaceae & Symplocos tenuifolia Brand & & A & $\mathrm{A}$ & $\mathrm{CL}$ & Zoo \\
\hline \multirow{2}{*}{ Urticaceae } & Boehmeria caudata $\mathrm{Sw}$. & AR & $\mathrm{A}$ & & $\mathrm{P}$ & Auto \\
\hline & Cecropia glaziovii Snethl. & $\mathrm{AR}$ & AR & $\mathrm{AR}$ & $\mathrm{P}$ & Zoo \\
\hline
\end{tabular}

As famílias com maior número de espécies foram Fabaceae (17), Asteraceae (12), Myrtaceae (12), Rubiaceae (11) e Melastomataceae (nove), perfazendo um total de 43,3\% das espécies identificadas no presente estudo.

Os gêneros com maior número de espécies foram Piper (sete), Solanum (seis), Psychotria (cinco), Baccharis, Miconia, Myrcia, Nectandra e Vernonanthura (quatro), que corresponderam a 8,8\% do total de gêneros e contribuíram com $26,9 \%$ do total de espécies amostradas.

Dentre as 141 espécies amostradas, 127 ocorreram no estrato arbóreo e 79 no estrato regenerativo. A quantidade de espécies presentes nos dois estratos, arbóreo e regenerativo, foi maior no AT II (35) 
seguido por AT III (28) e AT I (26). No entanto, algumas espécies foram amostradas nos dois estratos dos três ambientes estudados: Hedyosmum brasiliense, Nectandra cuspidata, Tibouchina pilosa, Tibouchina urvelleana, Myrsine coriacea, Piper aduncum, Piper arboreum, Casearia sylvestris e Cecropia glaziovii. Estas espécies, pioneiras e exigentes em luz, encontraram as condições adequadas para o seu estabelecimento a partir do abandono da área e, possivelmente, continuam persistindo até períodos posteriores enquanto as condições ambientais são benéficas ao seu ingresso e estabelecimento.

Em relação aos grupos ecológicos, 36 espécies foram classificadas como pioneiras, 60 como clímax exigentes de luz e 45 como clímax tolerantes à sombra. No AT I foram registrados 27, 38 e 36 espécies pioneiras, clímax exigentes de luz e clímax tolerantes à sombra, respectivamente. A predominância de espécies clímax exigentes de luz (38) e clímax tolerantes a sombra (36) verificada na AT I indica que a vegetação nesta área encontra-se em estágio inicial mais avançado de sucessão quando comparado com os outros ambientes. Para a AT II foram registrados 26, 41 e 28 espécies, pioneiras, clímax exigentes em luz e clímax tolerantes à sombra, respectivamente. A maior presença de espécies clímax exigentes em luz (41) é decorrente do menor período de abandono da área e de sua regeneração, em comparação com a AT I. Já no AT III foram registrados 27, 29 e 23 espécies pioneiras, clímax exigentes em luz e clímax tolerantes à sombra, respectivamente. A predominância de espécies clímax exigentes em luz (29) e pioneiras (27), bem como o menor número de espécies clímax tolerantes à sombra, comprova que a AT III se encontra em processo de sucessão menos avançado quando comparada com os outros ambientes estudados.

A distribuição dos grupos ecológicos das espécies nos três ambientes (Figura 1) também evidencia que essa distribuição no estrato arbóreo é ligeiramente diferente em relação ao estrato regenerativo. Neste último, observa-se uma menor participação das espécies pioneiras e uma maior porcentagem de espécies clímax tolerantes à sombra, nos três ambientes.

A análise da distribuição do número de indivíduos nos respectivos grupos ecológicos (Figuras 2 e 3 ) mostrou que há maior distinção entre os grupos para esse parâmetro. No estrato arbóreo, as espécies pioneiras agregam mais de $50 \%$ dos indivíduos, nos três ambientes, seguidas do grupo das clímax exigentes em luz com valores próximos de $35 \%$, enquanto que as clímax tolerantes à sombra agregam aproximadamente $15 \%$.

Por outro lado, no estrato regenerativo observa-se um nítido decréscimo de espécies pioneiras com



- Pioneiras \% Clímax exigentes em luz + Clímax tolerantes à sombra

FIGURA 1: Distribuição dos grupos ecológicos de espécies, por ambiente e por estrato, nos três ambientes em abandono após a extração de Eucalyptus grandis Hill ex Maiden em Brusque - SC. AT $\mathrm{I}=$ Ambiente com 5 anos de abandono; AT II = Ambiente com 3 anos de abandono; AT $\mathrm{III}=$ Ambiente com 1,5 anos de abandono; $\mathrm{A}=$ estrato arbóreo; $\mathrm{R}=$ estrato regenerativo.

FIGURE 1: Distribution of ecological groups of species, for the environment and for each stratum in all three environments that have been abandoned after the extraction of Eucalyptus grandis Hill ex Maiden in Brusque, SC state. I = AT environment with 5 years of abandonment, AT II = Environment with 3 years of neglect; AT III = environmenet with 1.5 years of abandonment, $\mathrm{A}=$ tree layer, $\mathrm{R}=$ regenerative stratum. 


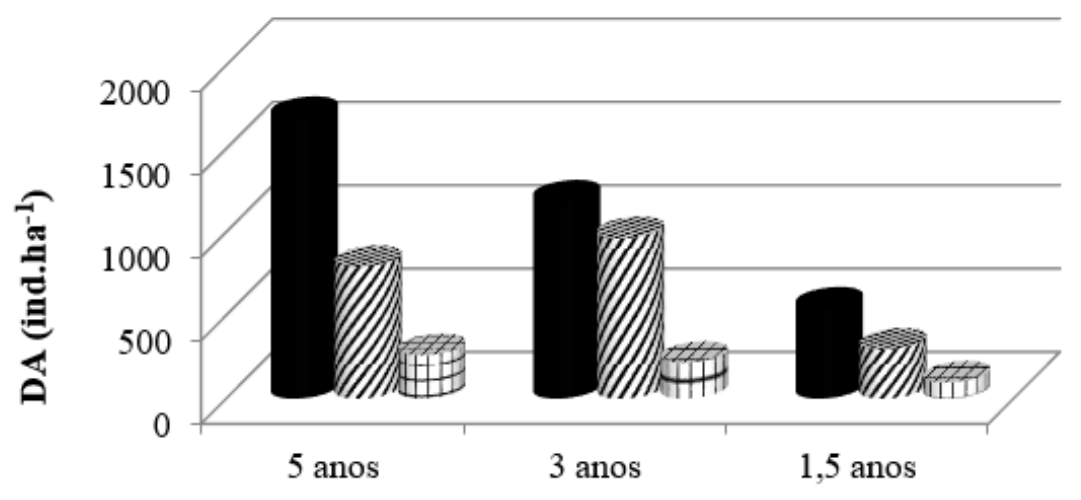

- Pioneiras " Clímax exigentes em luz $\sqcap$ Clímax tolerantes à sombra

FIGURA 2: Distribuição do número de indivíduos por grupos ecológicos de espécies, por ambiente no estrato arbóreo, nos três ambientes em abandono após a extração de Eucalyptus grandis Hill ex Maiden em Brusque - SC. AT I = Ambiente com 5 anos de abandono; AT II = Ambiente com 3 anos de abandono; AT III = Ambiente com 1,5 anos de abandono.

FIGURE 2: Distribution of individuals by ecological groups of species for the environment in the arboreum stratum in all three environments that have been abandoned after the extraction of Eucalyptus grandis Hill ex Maiden in Brusque-SC. I = AT environment with 5 years of abandonment, $\mathrm{AT}=$ Environment II with 3 years of abandonment; AT III = environment with 1.5 years of abandonment.

o avanço da idade de regeneração, passando de $45 \%$ na idade 1,5 para valores inferiores a $15 \%$ na idade de 5 anos. Nesse estrato, as espécies clímax tolerantes à sombra, que na idade 1,5 agregam próximo de $45 \%$ dos indivíduos, passam a deter mais de $60 \%$ da densidade na idade de 5 anos. Neste estrato também se torna evidente a diminuição da densidade total de plantas com o avanço da idade de regeneração, resultante

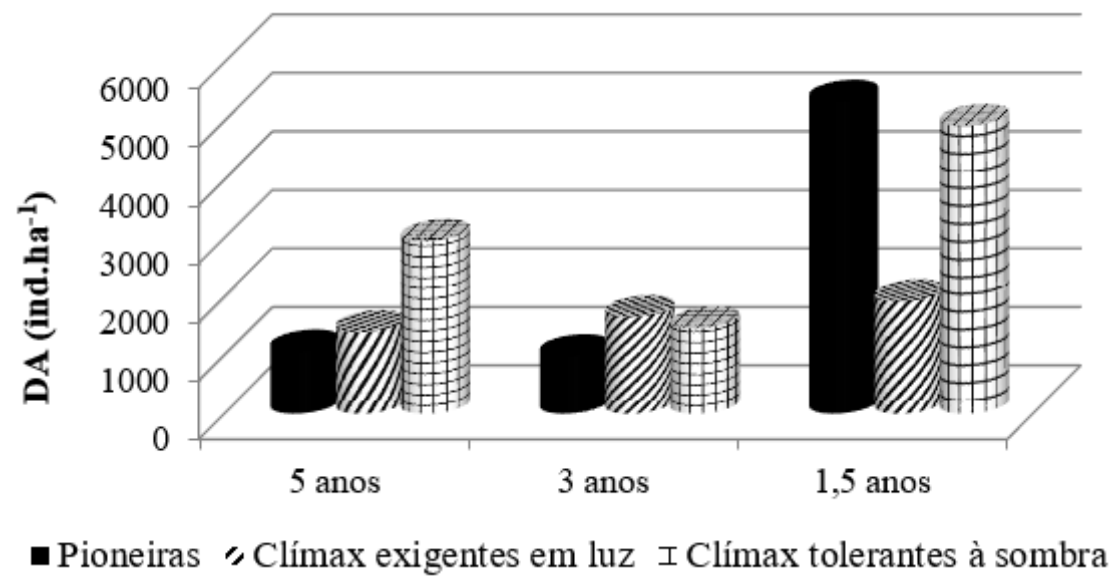

FIGURA 3: Distribuição do número de indivíduos por grupos ecológicos de espécies, por ambiente no estrato regenerativo, nos três ambientes em abandono após a extração de Eucalyptus grandis Hill ex Maiden em Brusque - SC. AT I = Ambiente com 5 anos de abandono; AT II = Ambiente com 3 anos de abandono; AT III = Ambiente com 1,5 anos de abandono.

FIGURE 3: Distribution of individuals by ecological groups of species for the environment and for each stratum in all three environments that have been abandoned after the extraction of Eucalyptus grandis Hill ex Maiden in Brusque, SC state. I = AT environment with 5 years of abandonment, AT = Environment II with 3 years of neglect; Environment with AT III = 1.5 years of abandonment, $\mathrm{A}=$ tree layer, $\mathrm{R}=$ regenerative stratum. 
principalmente da diminuição de indivíduos das espécies pioneiras (Figura 3).

Esses resultados mostram que no período analisado de cinco anos, observa-se uma dinâmica na composição da vegetação evidenciando a ação do processo sucessional na recuperação da área.

Os resultados de distribuição de indivíduos por grupos ecológicos mostram que o processo de regeneração encontra-se bem estabelecido, ainda que em fase inicial. Isto está evidenciado pelo estabelecimento já consolidado, majoritariamente por espécies pioneiras no extrato arbóreo (Figura 2). O gradiente de espécies totais nesse extrato, no sentido da maior idade de abandono, também evidencia que o processo de regeneração está diretamente relacionado ao tempo.

A diminuição relativa do grupo pioneiras no estrato regenerativo é um indicativo de que o processo de estabelecimento dessas espécies está avançado, em fase terminal (Figura 3). Ao mesmo tempo se encontra em franco desenvolvimento para os grupos clímax exigentes em luz e clímax tolerantes à sombra. Contrariamente ao extrato arbóreo, nesse estrato regenerativo, a relação entre quantidades totais de indivíduos é inversa à idade de abandono, confirmando o bom estabelecimento do processo de regeneração. Além da confirmação da relação direta entre este processo e o tempo.

Dentre as 141 espécies amostradas, $104(73,8 \%)$ apresentaram síndrome de dispersão por animais (zoocórica), estratégia de dispersão mais frequente encontrada nas florestas tropicais (HOWE; SMALLWOOD, 1982; IBARRA-MANRÍQUEZ et al., 1991; MORELLATO et al., 2000; NEGRELLE, 2002). As espécies anemocóricas e autocóricas contribuíram com apenas 27 e 10 (26,2\%) respectivamente. Carvalho (2010) avaliou a síndrome de dispersão em 12 fragmentos de Floresta Ombrófila Submontana no Rio de Janeiro e encontrou valores de $63,7 \%$ a $72,9 \%$ para as espécies com síndrome de dispersão zoocórica em florestas secundárias.

$\mathrm{O}$ número de espécies do estrato arbóreo nos três ambientes aumentou com o período de regeneração após a retirada de Eucalyptus grandis (Tabela 2). O AT I com cinco anos em processo de regeneração apresentou maior número de espécies (91) quando comparado com o AT II (78) e AT III (60), respectivamente. Já no estrato regenerativo, AT II apresentou número de espécies mais elevada (52) quando comparado com AT I (36) e AT III (47), respectivamente. O maior número de espécies em AT I e AT II, nos estratos, arbóreo e regenerativo, respectivamente, pode estar relacionado às idades da vegetação em regeneração e também à maior proximidade destas duas áreas com outras florestas naturais remanescentes.

TABELA 2: Resumo dos parâmetros analisados para as espécies nos três ambientes estudados em áreas abandonadas após a extração de Eucalyptus grandis Hill ex Maiden em Brusque - SC.

TABLE 2: Summary of the parameters analyzed for the species studied in three environments in areas abandoned after the extraction of Eucalyptus grandis Hill ex Maiden in Brusque, SC state.

\begin{tabular}{|c|c|c|c|c|c|c|}
\hline \multirow{2}{*}{ Parâmetros } & \multicolumn{3}{|c|}{ Estrato arbóreo } & \multicolumn{3}{|c|}{ Estrato regenerativo } \\
\hline & AT I & AT II & AT III & AT I & AT II & AT III \\
\hline Área amostral $\left(\mathrm{m}^{2}\right)$ & 3.800 & 4.200 & 3.200 & 360 & 420 & 340 \\
\hline Famílias & 35 & 31 & 28 & 20 & 25 & 22 \\
\hline Gêneros & 66 & 57 & 41 & 29 & 40 & 34 \\
\hline Espécies & 91 & 78 & 60 & 36 & 52 & 47 \\
\hline $\mathrm{N}^{\circ}$ indivíduos & 1.065 & 993 & 301 & 194 & 171 & 413 \\
\hline Densidade (ind.ha ${ }^{-1}$ ) & 2.803 & 2.364 & 941 & 5.389 & 4.071 & 12.147 \\
\hline Shannon (nats.ind ${ }^{-1}$ ) & 3,51 & 3,47 & 3,44 & 2,96 & 3,62 & 3,01 \\
\hline Pielou & 0,78 & 0,80 & 0,84 & 0,83 & 0,92 & 0,78 \\
\hline
\end{tabular}

Os valores do índice de Shannon (H') para o estrato arbóreo em AT I, II e III foram de 3,51, 3,47 e 3,44 e a equabilidade de Pielou (J') foi de 0,78, 0,80 e 0,84, respectivamente. Estes valores foram próximos aos encontrados em outros estudos na Floresta Ombrófila Densa em Santa Catarina por Siminski et al. (2004). Mantovani et al. (2005) em uma Floresta Ombrófila Densa na região de São Pedro de Alcântara encontraram valores de H' entre 3,19 a 4,14 e de 0,73 a 0,91 para J'; Colonetti et al. (2009), em estudo realizado em uma Floresta Ombrófila Densa Submontana no sul de Santa Catarina, obtiveram valores de 
3,23 para H' e de 0,69 para J'; Lingner et al. (2013) obtiveram valores médios de 2 a 4,2 para H' e de 0,54 a 0,94 para J' no inventário florístico-florestal da Floresta Ombrófila Densa Submontana no Estado de Santa Catarina. Deve-se considerar que diversos fatores podem interferir nos resultados desses índices, incluindo limites de inclusão adotados nos levantamentos e histórico de uso da área, por isso, as comparações devem ser vistas com ressalvas. A diversidade no estrato arbóreo para os três ambientes estudados foi crescente, aumentando conforme a idade de regeneração, evidenciando a existência de relação entre a diversidade de espécies com a idade de regeneração, para os períodos estudados.

Os valores de J' no estrato arbóreo mostraram uma distribuição relativamente equilibrada no AT III, fato que pode ser atribuído ao menor número de espécies e indivíduos. Por tratar-se de um ambiente com início de colonização recente pode-se considerar que a competição não se manifestou ainda e não evidenciou a dominância de espécies nesta área. Para os AT I e II o número de indivíduos foi superior, porém, já se acentuaram as diferenças no número de indivíduos entre as espécies em função da competição.

Para o estrato regenerativo pode-se observar que o AT II obteve o maior valor de H' $(3,62)$ quando comparado com o AT I $(2,96)$ e AT III $(3,01)$, respectivamente. O valor de H' encontrado no AT II está associado ao maior número de espécies amostradas, bem como à elevada equidade das mesmas (Tabela 2). Os valores de H' encontrados nos três ambientes são, em geral, superiores aos encontrados em outros estudos neste estrato, como é o caso de Nóbrega et al. (2008) que, em levantamentos da regeneração natural em dois remanescentes naturais, obtiveram valores de $\mathrm{H}^{\prime}=1,9$ e 2,1 , em vegetação de várzea do Rio Mogi-Guaçu - SP. No entanto, deve-se considerar que os estudos de Nóbrega et al. (2008) foram realizados em áreas de solos caracterizados como Neossolo Flúvico Distrófico, mais úmidos e limitantes ao estabelecimento de espécies vegetais em relação aos solos no presente estudo, que foram caracterizados como Argissolo Vermelho-Amarelo. Os valores de H' obtidos no presente estudo também são coerentes com aqueles encontrados por Meyer et al. (2013) no estrato regenerativo da Floresta Ombrófila Densa Submontana em Santa Catarina, que apresentaram valores de 1,86 a 4,27.

Já a equabilidade de Pielou no estrato regenerativo foi maior em AT II $\left(\mathrm{J}^{\prime}=0,92\right)$, seguida de AT I com J' $=0,83$ e AT III com J'=0,78. AT II caracteriza-se por conter uma distribuição mais equilibrada entre espécies e consequentemente maior valor de equabilidade, quando comparado com os demais ambientes. Os valores obtidos para J' no presente trabalho foram superiores aos encontrados por Nóbrega et al. (2008) no estrato regenerativo de mata ciliar em Mogi-Guaçu $\left(\mathrm{J}^{\prime}=0,70\right)$, evidenciando o efeito de variáveis ambientais no comportamento da vegetação e, nesse caso, as características dos solos. Os resultados, de forma geral, são compatíveis com aqueles obtidos para o estrato regenerativo da Floresta Ombrófila Densa Submontana em Santa Catarina, em que Meyer et al. (2013) obtiveram valores de 0,62 a 0,98.

Os resultados obtidos para os parâmetros fitossociológicos, nos estratos arbóreo e regenerativo, encontram-se na Tabela 3. A maior densidade de indivíduos foi obtida no AT I, quando comparada com a AT II e AT III. As espécies Myrsine coriacea, Mimosa bimucronata, Cecropia glaziovii, Tibouchina urvilleana e Myrcia splendens apresentaram 44\% do total de indivíduos no estrato arbóreo do AT I. No AT II, as espécies Mimosa bimucronata, Myrcia splendens, Cecropia glaziovii, Myrsine coriacea e Jacaranda puberula apresentaram $40,4 \%$ do total de indivíduos do estrato arbóreo. Para o AT III, as espécies com maior número de indivíduos foram Tibouchina urvilleana, Cecropia glaziovii, Mimosa bimucronata, Myrcia splendens e Nectandra cuspidata que contribuíram com $42,5 \%$ da densidade total.

No estrato regenerativo, a maior densidade de indivíduos foi registrada no AT III, valor muito superior ao registrado nos outros ambientes. No AT I, as duas espécies com maiores valores de densidade no estrato regenerativo foram Leandra dasytricha e Psychotria officinalis que apresentaram 10,8\% e 8,3\% do total de indivíduos levantados respectivamente. No AT II, Psychotria suterella e Myrcia splendens contribuíram com $8,2 \%$ e $6,4 \%$ do total de indivíduos. Já no AT III, as espécies com maiores valores de densidade foram Psychotria suterella e Psidium cattleianum com 13,8\% e 5,3\% do total de indivíduos, respectivamente.

$\mathrm{O}$ valor de densidade encontrado no estrato regenerativo para o AT III pode estar relacionado com a idade e fase sucessional nesta área, mais jovem (um ano e meio em regeneração) e com predominância de espécies herbáceas e arbustivas. Os indivíduos encontrados nas unidades amostrais no AT III estavam representados mais expressivamente no estrato regenerativo do que no arbóreo, comprovando que esta área encontra-se em um processo de regeneração natural mais recente. 
A frequência absoluta nos três ambientes foi relativamente baixa para a maioria das espécies (Figura 4). No ambiente I, houve maior número de espécies com frequência superior a $50 \%$, tanto no estrato arbóreo quanto no regenerativo. No entanto, a porcentagem de espécies de maior frequência foi decrescente do ambiente I para os ambientes II e III. Já no estrato regenerativo, somente foram encontradas espécies com frequência superior a $50 \%$ no ambiente I. Nesse estrato, mais de $80 \%$ das espécies apresentaram frequência inferior a $20 \%$. Esses resultados evidenciam que poucas espécies estão amplamente distribuídas nas áreas em estudo, fato esperado para áreas em regeneração ainda incipiente.

Destaca-se que no AT III, apenas Tibouchina urvilleana apresentou frequência superior a 50\%, mostrando ser uma espécie de elevado potencial de dispersão e instalação nas áreas em estudo.

No estrato regenerativo, apenas Piper aduncum e Piper arboreum apresentaram frequência superior a 50\% no ambiente I; No AT II não foram registradas frequências superiores a 50\% e Hedyosmum brasiliense e Myrsine coriacea foram as espécies mais frequentes $(28,6 \%)$. No AT III também não foram registradas frequências superiores a $50 \%$ e apenas Tibouchina urvilleana, Piper arboreum e Psidium cattleianum apresentaram frequência superiores a $40 \%$.

Nos três ambientes avaliados, as espécies com maior densidade e frequência pertencem ao grupo das pioneiras e clímax exigente em luz. Esse resultado é esperado, uma vez que as principais espécies colonizadoras de grandes clareiras pertencem a estes grupos ecológicos. Resultados semelhantes foram obtidos por Alvarenga et al. (2006) em áreas de floresta ripária perturbadas e degradadas.

Os resultados também apontaram que no processo de regeneração das três áreas avaliadas, observouse aumento dos parâmetros florísticos e estruturais com o aumento das idades, destacando-se a riqueza de espécies e do percentual de espécies clímax exigentes de luz. Outros estudos, envolvendo os processos sucessionais na Floresta Atlântica, não necessariamente em ambiente ciliar, demonstraram essas mesmas tendências (KLEIN, 1980; TABARELLI; MANTOVANI, 1999; CHEUNG, 2006; VENZKE; MARTINS, 2013).

Cecropia glaziovii e Mimosa bimucronata estão presentes entre as espécies com maiores valores de densidade no estrato arbóreo dos três ambientes estudados, isto se deve ao fato de serem espécies pioneiras e colonizadoras de formações secundárias no vale do Itajaí (KLEIN, 1980). Observa-se que Cecropia

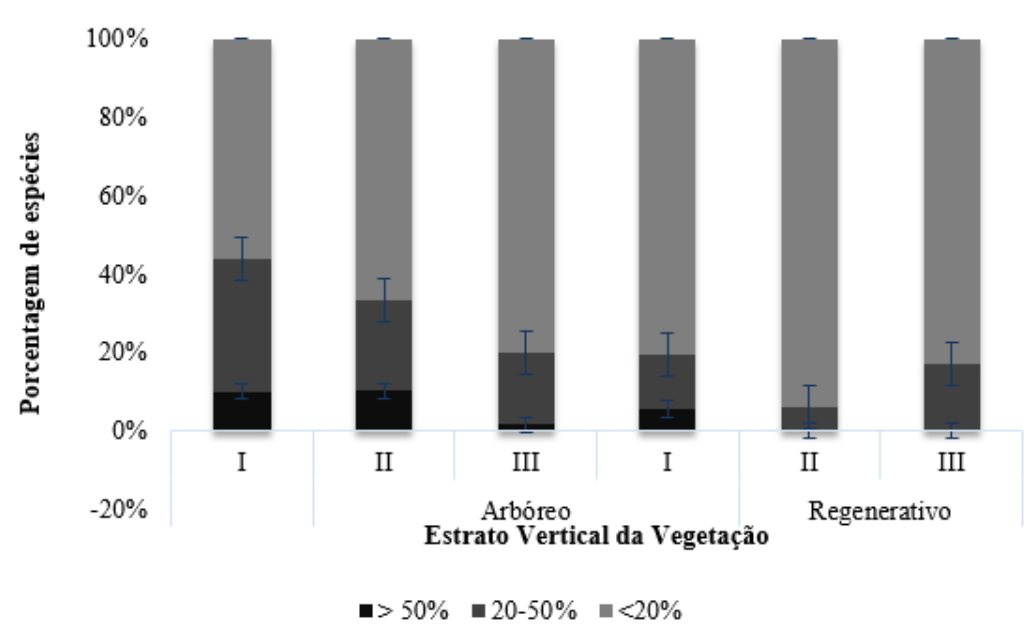

FIGURA 4: Distribuição das espécies por classes de frequência absoluta e por ambiente, nos estratos arbóreo e regenerativo, em áreas de abandono após a extração de Eucalyptus grandis Hill ex Maiden em Brusque - SC. AT I = Ambiente com 5 anos de abandono; AT II = Ambiente com 3 anos de abandono; AT III = Ambiente com 1,5 anos de abandono.

FIGURE 4: Distribution of species by absolute frequency of classes and environment, in the arboreal and regenerative stratum, abandoned areas after the Eucalyptus grandis Hill ex Maiden extraction in Brusque, SC state. AT I = Environment with 5 years of abandonment; AT II = Environment with 3 years of abandonment; AT III = Environment 1.5 years of abandonment. 
glaziovii é característica do terço inferior de encostas, onde justamente os ambientes são mais suscetíveis a alterações antrópicas (BORÉM; RAMOS, 2001). Já a expressiva densidade de Mimosa bimucronata pode estar relacionada à sua afinidade com a umidade do solo ao longo dos cursos d'água nos ambientes estudados (REITZ et al., 1979). Myrsine coriacea também apresentou alta densidade nos ambientes I e II sendo mais reduzida no ambiente III. Esta espécie foi encontrada com alta densidade de indivíduos por Siminski et al. (2004) e por Scariot e Reis (2010) em áreas de sucessão secundária e de regeneração natural. Além de ser uma espécie zoocórica e que, portanto, oferece recursos alimentares à fauna, também tem um papel importante na colonização de áreas abertas que sofreram perturbações (SCARIOT; REIS, 2010). De acordo com Klein (1980), a presença de espécies do gênero Myrsine surge como substituta das espécies arbustivas e arbóreas do gênero Baccharis e várias ervas e pioneiras.

TABELA 3: Parâmetros fitossociológicos nos estratos arbóreo e regenerativo, nos três ambientes em abandono, após extração de Eucalyptus grandis Hill ex Maiden em Brusque - SC. DA = densidade absoluta (ind.ha-1 ${ }^{-1}$ e $\mathrm{FA}=$ frequência absoluta (\%).

TABLE 3: Phytosociological parameters for arboreal and regenerative stratum sampled in three environments that have been abandoned after extraction of Eucalyptus grandis Hill ex Maiden in Brusque, $\mathrm{SC}$ state. $\mathrm{DA}=$ absolute density $\left(\right.$ ind.ha $\left.{ }^{-1}\right)$ and $\mathrm{FA}=$ absolute frequency (\%).

\begin{tabular}{|c|c|c|c|c|c|c|c|c|c|c|c|c|}
\hline \multirow{3}{*}{ ESPÉCIES } & \multicolumn{6}{|c|}{ Estrato arbóreo } & \multicolumn{6}{|c|}{ Estrato regenerativo } \\
\hline & \multicolumn{2}{|c|}{ AT I } & \multicolumn{2}{|c|}{ AT II } & \multicolumn{2}{|c|}{ AT III } & \multicolumn{2}{|c|}{ AT I } & \multicolumn{2}{|c|}{ AT II } & \multicolumn{2}{|c|}{ AT III } \\
\hline & DA & FA & DA & FA & DA & FA & DA & FA & DA & FA & DA & FA \\
\hline Abarema langsdorffii & & & 11,9 & 9,5 & 3,1 & 6,3 & & & & & & \\
\hline Aegiphila integrifolia & 15,8 & 21,1 & 23,8 & 19,0 & & & & & & & & \\
\hline Aegiphila obducta & 15,8 & 10,5 & 23,8 & 19,0 & & & & & & & & \\
\hline Alchornea glandulosa & 55,3 & 52,6 & 21,4 & 33,3 & 15,6 & 12,5 & & & 23,8 & 4,8 & 29,4 & 5,9 \\
\hline Alchornea triplinervia & 39,5 & 57,9 & 23,8 & 19,0 & & & & & 23,8 & 4,8 & & \\
\hline Amaioua guianensis & & & 2,4 & 4,8 & & & & & & & & \\
\hline Andira fraxinifolia & 2,6 & 5,3 & & & & & & & & & & \\
\hline Aniba firmula & & & & & 6,3 & 6,3 & & & 23,8 & 4,8 & & \\
\hline Annona cacans & 10,5 & 21,1 & 2,4 & 4,8 & & & & & 47,6 & 9,5 & & \\
\hline Annona neosericea & 23,7 & 26,3 & & & & & & & & & & \\
\hline Annona sylvatica & 7,9 & 10,5 & & & & & 27,8 & 5,6 & & & & \\
\hline Aspidosperma australe & 2,6 & 5,3 & & & & & & & & & & \\
\hline $\begin{array}{l}\text { Austroeupatorium } \\
\text { inulaefolium }\end{array}$ & & & & & 6,3 & 12,5 & & & & & & \\
\hline Baccharis dracunculifolia & 15,8 & 21,1 & & & 15,6 & 12,5 & & & & & & \\
\hline Baccharis microdonta & & & & & 3,1 & 6,3 & & & & & 88,2 & 11,8 \\
\hline Baccharis punctulata & & & 2,4 & 4,8 & & & & & & & & \\
\hline Baccharis semiserrata & 26,3 & 31,6 & 35,7 & 28,6 & 15,6 & 18,8 & & & & & 147,1 & 23,5 \\
\hline Bactris setosa & & & & & & & & & 71,4 & 14,3 & & \\
\hline Bathysa australis & 50,0 & 31,6 & 38,1 & 38,1 & & & 27,8 & 5,6 & 23,8 & 4,8 & & \\
\hline Boehmeria caudata & 10,5 & 10,5 & 83,3 & 19,0 & & & 27,8 & 5,6 & & & & \\
\hline Brosimum lactescens & 2,6 & 5,3 & & & & & & & & & & \\
\hline Bunchosia maritima & 5,3 & 5,3 & & & & & & & & & 88,2 & 5,9 \\
\hline Cabralea canjerana & 28,9 & 26,3 & & & & & 111,1 & 16,7 & 23,8 & 4,8 & & \\
\hline Calyptranthes lucida & & & 2,4 & 4,8 & & & & & & & & \\
\hline Campomanesia reitziana & 28,9 & 42,1 & 40,5 & 38,1 & & & 55,6 & 5,6 & 23,8 & 4,8 & 205,9 & 23,5 \\
\hline Casearia decandra & 21,1 & 31,6 & 4,8 & 9,5 & 18,8 & 18,8 & & & & & & \\
\hline Casearia sylvestris & 15,8 & 26,3 & 23,8 & 38,1 & 25,0 & 31,3 & 27,8 & 5,6 & 71,4 & 14,3 & 970,6 & 17,6 \\
\hline Cecropia glaziovii & 239,5 & 89,5 & 154,8 & 66,7 & 68,8 & 50,0 & 27,8 & 5,6 & 95,2 & 9,5 & 205,9 & 17,6 \\
\hline
\end{tabular}

Continua... 
TABELA 3: Continuação...

TABLE 3: Continued...

\begin{tabular}{|c|c|c|c|c|c|c|c|c|c|c|c|c|}
\hline \multirow{3}{*}{ ESPÉCIES } & \multicolumn{6}{|c|}{ Estrato arbóreo } & \multicolumn{6}{|c|}{ Estrato regenerativo } \\
\hline & \multicolumn{2}{|c|}{ AT I } & \multicolumn{2}{|c|}{ AT II } & \multicolumn{2}{|c|}{ AT III } & \multicolumn{2}{|c|}{ AT I } & \multicolumn{2}{|c|}{ AT II } & \multicolumn{2}{|c|}{ AT III } \\
\hline & $\mathrm{DA}$ & FA & DA & FA & DA & FA & DA & FA & DA & FA & DA & FA \\
\hline Cedrela fissilis & 15,8 & 21,1 & & & & & & & & & & \\
\hline Chrysophyllum inornatum & & & 2,4 & 4,8 & & & & & & & & \\
\hline Clethra scabra & 7,9 & 5,3 & 2,4 & 4,8 & & & & & & & & \\
\hline Cordia silvestris & 26,3 & 26,3 & & & & & & & & & & \\
\hline Coussarea contracta & 5,3 & 5,3 & & & & & & & & & & \\
\hline Cryptocarya moschata & & & 9,5 & 14,3 & & & & & & & & \\
\hline Cupania vernalis & 28,9 & 31,6 & 38,1 & 47,6 & 31,3 & 43,8 & & & 166,7 & 23,8 & 58,8 & 11,8 \\
\hline Dahlstedtia pentaphylla & 5,3 & 10,5 & & & & & & & & & & \\
\hline Dalbergia frutescens & & & 9,5 & 19,0 & & & & & 23,8 & 4,8 & & \\
\hline Dalbergia brasiliensis & & & 11,9 & 19,0 & & & & & 190,5 & 9,5 & & \\
\hline Endlicheria paniculata & 26,3 & 26,3 & 11,9 & 9,5 & 3,1 & 6,3 & 55,6 & 11,1 & & & & \\
\hline $\begin{array}{l}\text { Enterolobium } \\
\text { contortisiliquum }\end{array}$ & & & & & 3,1 & 6,3 & & & & & & \\
\hline Esenbeckia grandiflora & & & & & & & 27,8 & 5,6 & & & 205,9 & 5,9 \\
\hline Eugenia brasiliensis & 2,6 & 5,3 & & & & & & & & & & \\
\hline Eugenia catharinensis & & & & & & & & & 47,6 & 9,5 & & \\
\hline Eugenia kleinii & 2,6 & 5,3 & & & & & & & 23,8 & 4,8 & 117,6 & 5,9 \\
\hline Euterpe edulis & 10,5 & 15,8 & & & 15,6 & 12,5 & 55,6 & 5,6 & & & & \\
\hline Ficus adhatodifolia & 21,1 & 26,3 & 57,1 & 52,4 & 6,3 & 6,3 & & & 119,0 & 9,5 & & \\
\hline Ficus cestrifolia & 2,6 & 5,3 & & & & & & & & & & \\
\hline Guapira opposita & 5,3 & 5,3 & & & & & & & 23,8 & 4,8 & & \\
\hline Guarea macrophylla & 10,5 & 21,1 & 4,8 & 9,5 & 9,4 & 18,8 & 55,6 & 11,1 & & & 58,8 & 11,8 \\
\hline Guatteria australis & & & 9,5 & 9,5 & 12,5 & 18,8 & & & 23,8 & 4,8 & & \\
\hline Hedyosmum brasiliense & 18,4 & 21,1 & 4,8 & 4,8 & 6,3 & 12,5 & 27,8 & 5,6 & 214,3 & 28,6 & 88,2 & 17,6 \\
\hline Hieronyma alchorneoides & 26,3 & 31,6 & 97,6 & 66,7 & 3,1 & 6,3 & 27,8 & 5,6 & 71,4 & 9,5 & & \\
\hline Ilex brevicuspis & 7,9 & 10,5 & & & & & & & & & & \\
\hline Ilex dumosa & 2,6 & 5,3 & 2,4 & 4,8 & 6,3 & 6,3 & & & & & & \\
\hline Ilex theezans & & & 2,4 & 4,8 & & & & & & & & \\
\hline Inga marginata & 63,2 & 42,1 & 40,5 & 23,8 & & & & & & & & \\
\hline Jacaranda puberula & 21,1 & 42,1 & 131,0 & 47,6 & 25,0 & 31,3 & & & 23,8 & 4,8 & 323,5 & 29,4 \\
\hline Leandra dasytricha & 2,6 & 5,3 & & & & & 583,3 & 22,2 & & & & \\
\hline Leandra regnellii & 2,6 & 5,3 & & & & & 416,7 & 38,9 & 119,0 & 4,8 & & \\
\hline Lonchocarpus campestris & & & 9,5 & 9,5 & & & & & & & & \\
\hline $\begin{array}{l}\text { Lonchocarpus } \\
\text { guillemineanus }\end{array}$ & & & & & 3,1 & 6,3 & & & & & & \\
\hline Machaerium hirtum & 5,3 & 10,5 & 11,9 & 23,8 & & & & & 47,6 & 9,5 & 58,8 & 5,9 \\
\hline Magnolia ovata & 2,6 & 5,3 & 21,4 & 33,3 & 12,5 & 12,5 & & & & & & \\
\hline Margaritopsis astrellantha & & & & & & & 305,6 & 16,7 & & & & \\
\hline Matayba intermedia & 13,2 & 21,1 & 21,4 & 28,6 & & & 55,6 & 5,6 & 71,4 & 14,3 & 58,8 & 5,9 \\
\hline Maytenus robusta & & & & & & & 27,8 & 5,6 & & & 29,4 & 5,9 \\
\hline Miconia cabucu & 15,8 & 10,5 & 7,1 & 9,5 & & & & & 95,2 & 9,5 & & \\
\hline Miconia cinnamomifolia & 5,3 & 10,5 & 2,4 & 4,8 & & & & & 47,6 & 9,5 & 117,6 & 5,9 \\
\hline Miconia latecrenata & 15,8 & 21,1 & & & & & 27,8 & 5,6 & 71,4 & 9,5 & & \\
\hline
\end{tabular}

Continua...

Ci. Fl., v. 27, n. 1, jan.-mar., 2017 
TABELA 3: Continuação...

TABLE 3: Continued...

\begin{tabular}{|c|c|c|c|c|c|c|c|c|c|c|c|c|}
\hline \multirow{3}{*}{ ESPÉCIES } & \multicolumn{6}{|c|}{ Estrato arbóreo } & \multicolumn{6}{|c|}{ Estrato regenerativo } \\
\hline & \multicolumn{2}{|c|}{ AT I } & \multicolumn{2}{|c|}{ AT II } & \multicolumn{2}{|c|}{ AT III } & \multicolumn{2}{|c|}{ AT I } & \multicolumn{2}{|c|}{ AT II } & \multicolumn{2}{|c|}{ AT III } \\
\hline & DA & FA & DA & FA & DA & FA & DA & FA & DA & FA & DA & FA \\
\hline Miconia valtheri & 2,6 & 5,3 & 4,8 & 4,8 & & & & & & & & \\
\hline Mimosa bimucronata & 289,5 & 94,7 & 264,3 & 66,7 & 65,6 & 43,8 & & & 95,2 & 14,3 & 264,7 & 23,5 \\
\hline Mimosa scabrella & & & & & 3,1 & 6,3 & & & & & & \\
\hline Mollinedia schottiana & 5,3 & 10,5 & 2,4 & 4,8 & 3,1 & 6,3 & & & & & & \\
\hline Mollinedia triflora & & & & & 3,1 & 6,3 & 111,1 & 16,7 & 119,0 & 19,0 & 235,3 & 5,9 \\
\hline Myrceugenia myrcioides & 5,3 & 10,5 & & & & & 27,8 & 5,6 & & & & \\
\hline Myrcia hebepetala & & & 4,8 & 9,5 & 3,1 & 6,3 & & & 23,8 & 4,8 & 58,8 & 5,9 \\
\hline Myrcia pubipetala & & & & & 18,8 & 18,8 & & & & & 58,8 & 11,8 \\
\hline Myrcia spectabilis & 13,2 & 15,8 & & & & & & & & & & \\
\hline Myrcia splendens & 171,1 & 42,1 & 261,9 & 71,4 & 56,3 & 50,0 & & & 261,9 & 14,3 & 88,2 & 11,8 \\
\hline Myrsine coriacea & 355,3 & 84,2 & 145,2 & 81,0 & 28,1 & 43,8 & 166,7 & 22,2 & 238,1 & 28,6 & 147,1 & 29,4 \\
\hline Myrsine hermogenesii & & & & & & & & & & & 88,2 & 5,9 \\
\hline Nectandra cuspidata & 115,8 & 63,2 & 100,0 & 71,4 & 46,9 & 31,3 & 111,1 & 11,1 & 23,8 & 4,8 & 147,1 & 11,8 \\
\hline Nectandra grandiflora & & & & & 3,1 & 6,3 & & & & & & \\
\hline Nectandra oppositifolia & 36,8 & 36,8 & 11,9 & 19,0 & 34,4 & 31,3 & 55,6 & 11,1 & & & 58,8 & 5,9 \\
\hline Nectandra puberula & & & & & 3,1 & 6,3 & & & & & & \\
\hline Ocotea puberula & 2,6 & 5,3 & 7,1 & 4,8 & 3,1 & 6,3 & & & 23,8 & 4,8 & 58,8 & 11,8 \\
\hline Pera glabrata & 5,3 & 10,5 & 4,8 & 9,5 & 6,3 & 6,3 & & & & & & \\
\hline Piper aduncum & 47,4 & 42,1 & 4,8 & 9,5 & 18,8 & 6,3 & 638,9 & 61,1 & 47,6 & 9,5 & 323,5 & 23,5 \\
\hline Piper arboreum & 18,4 & 26,3 & 2,4 & 4,8 & 21,9 & 43,8 & 750,0 & 55,6 & 142,9 & 19,0 & 1235,3 & 41,2 \\
\hline Piper cernuит & 5,3 & 10,5 & & & & & & & & & 264,7 & 5,9 \\
\hline Piper crassinervium & 2,6 & 5,3 & & & & & & & 95,2 & 9,5 & & \\
\hline Piper hispidinervum & 2,6 & 5,3 & & & & & & & & & & \\
\hline Piper lindbergii & & & 2,4 & 4,8 & 3,1 & 6,3 & 361,1 & 22,2 & 166,7 & 14,3 & 147,1 & 5,9 \\
\hline Piper solmsianum & & & & & & & 166,7 & 5,6 & & & & \\
\hline Piptadenia gonoacantha & 2,6 & 5,3 & & & & & & & & & & \\
\hline Piptocarpha axillaris & 13,2 & 10,5 & 35,7 & 28,6 & & & & & & & & \\
\hline Platymiscium floribundum & & & 2,4 & 4,8 & & & & & & & & \\
\hline Posoqueria latifolia & & & & & & & & & 23,8 & 4,8 & & \\
\hline Pseudobombax grandiflorum & 15,8 & 15,8 & & & & & & & & & & \\
\hline Psidium cattleianum & 15,8 & 21,1 & 4,8 & 9,5 & & & & & 71,4 & 9,5 & 647,1 & 41,2 \\
\hline Psidium guajava & 5,3 & 5,3 & & & 12,5 & 12,5 & & & 23,8 & 4,8 & 58,8 & 11,8 \\
\hline Psychotria carthagenensis & & & 14,3 & 9,5 & & & & & & & & \\
\hline Psychotria nuda & & & & & & & 250,0 & 5,6 & & & & \\
\hline Psychotria officinalis & & & & & & & 444,4 & 38,9 & 119,0 & 9,5 & 470,6 & 17,6 \\
\hline Psychotria suterella & 2,6 & 5,3 & & & & & 111,1 & 16,7 & 333,3 & 9,5 & 1676,5 & 11,8 \\
\hline Psychotria vellosiana & 2,6 & 5,3 & 7,1 & 9,5 & & & & & & & 29,4 & 5,9 \\
\hline Roupala brasiliensis & & & & & 3,1 & 6,3 & & & & & & \\
\hline Rudgea recurva & & & & & & & & & 23,8 & 4,8 & & \\
\hline Sapium glandulosum & 7,9 & 15,8 & 2,4 & 4,8 & & & & & & & & \\
\hline Schefflera morototoni & & & 2,4 & 5,8 & & & & & & & & \\
\hline Schizolobium parahyba & 5,3 & 5,3 & & & & & & & & & & \\
\hline Senna macranthera & 2,6 & 5,3 & & & 6,3 & 6,3 & & & & & & \\
\hline
\end{tabular}

Continua... 
TABELA 3: Continuação...

TABLE 3: Continued...

\begin{tabular}{|c|c|c|c|c|c|c|c|c|c|c|c|c|}
\hline \multirow{3}{*}{ ESPÉCIES } & \multicolumn{6}{|c|}{ Estrato arbóreo } & \multicolumn{6}{|c|}{ Estrato regenerativo } \\
\hline & \multicolumn{2}{|c|}{ AT I } & \multicolumn{2}{|c|}{ AT II } & \multicolumn{2}{|c|}{ AT III } & \multicolumn{2}{|c|}{ AT I } & \multicolumn{2}{|c|}{ AT II } & \multicolumn{2}{|c|}{ AT III } \\
\hline & $\mathrm{DA}$ & FA & $\mathrm{DA}$ & FA & DA & FA & DA & FA & $\mathrm{DA}$ & FA & DA & FA \\
\hline Sloanea guianensis & 5,3 & 10,5 & 2,4 & 4,8 & & & & & & & 58,8 & 5,9 \\
\hline Solanum caeruleum & & & 4,8 & 9,5 & & & & & & & & \\
\hline Solanum guaraniticum & 5,3 & 10,5 & 7,1 & 9,5 & 6,3 & 6,3 & & & 142,9 & 14,3 & & \\
\hline Solanum mauritianum & & & & & & & 111,1 & 16,7 & & & 58,8 & 5,9 \\
\hline Solanum paniculatum & & & & & 9,4 & 6,3 & & & & & & \\
\hline Solanum pseudoquina & 10,5 & 21,1 & 2,4 & 4,8 & 3,1 & 6,3 & & & & & & \\
\hline Solanum sanctae-catharinae & & & & & 3,1 & 6,3 & & & & & 88,2 & 11,8 \\
\hline Sorocea bonplandii & 2,6 & 5,3 & & & & & & & & & & \\
\hline Syagrus romanzoffiana & & & & & 3,1 & 6,3 & & & & & & \\
\hline Symphyopappus casarettoi & & & 4,8 & 4,8 & 3,1 & 6,3 & & & & & & \\
\hline Symphyopappus compressus & 107,9 & 57,9 & 76,2 & 28,6 & 18,8 & 18,8 & & & 47,6 & 9,5 & 176,5 & 11,8 \\
\hline Symplocos tenuifolia & & & 7,1 & 9,5 & 9,4 & 12,5 & & & & & & \\
\hline $\begin{array}{l}\text { Tabernaemontana } \\
\text { catharinensis }\end{array}$ & 7,9 & 10,5 & & & 3,1 & 6,3 & 27,8 & 5,6 & 47,6 & 9,5 & & \\
\hline Tetrorchidium rubrivenium & 2,6 & 5,3 & & & & & & & & & & \\
\hline Tibouchina pilosa & 165,8 & 68,4 & 85,7 & 47,6 & 15,6 & 6,3 & 27,8 & 5,6 & 47,6 & 4,8 & 176,5 & 17,6 \\
\hline Tibouchina pulchra & & & 7,1 & 9,5 & & & & & & & & \\
\hline Tibouchina urvilleana & 181,6 & 52,6 & 92,9 & 42,9 & 162,5 & 68,8 & 27,8 & 5,6 & 47,6 & 4,8 & 2500,0 & 47,1 \\
\hline Trema micrantha & 92,1 & 26,3 & 33,3 & 23,8 & 3,1 & 6,3 & & & 23,8 & 4,8 & & \\
\hline Trichilia lepidota & 7,9 & 15,8 & 14,3 & 23,8 & & & & & & & 29,4 & 5,9 \\
\hline Vernonanthura discolor & 2,6 & 5,3 & 2,4 & 4,8 & & & & & & & & \\
\hline Vernonanthura divaricata & 5,3 & 10,5 & 11,9 & 14,3 & 3,1 & 6,3 & & & & & & \\
\hline Vernonanthura puberula & 26,3 & 26,3 & 26,2 & 28,6 & 9,4 & 12,5 & & & 47,6 & 9,5 & 29,4 & 5,9 \\
\hline Vernonanthura tweediana & & & 9,5 & 19,0 & 12,5 & 25,0 & & & & & & \\
\hline Virola bicuhyba & & & & & & & 27,8 & 5,6 & 23,8 & 4,8 & & \\
\hline Vitex megapotamica & & & 2,4 & 4,8 & & & & & & & & \\
\hline Xylopia brasiliensis & 5,3 & 10,5 & 2,4 & 4,8 & 3,1 & 6,3 & & & & & 29,4 & 5,9 \\
\hline Xylosma prockia & & & & & & & & & & & 58,8 & 5,9 \\
\hline Zanthoxylum rhoifolium & 34,2 & 47,4 & 85,7 & 71,4 & 12,5 & 18,8 & & & & & & \\
\hline Zollernia ilicifolia & 2,6 & 5,3 & 2,4 & 4,8 & & & & & & & 29,4 & 5,9 \\
\hline Total & $2.810,5$ & $1.936,8$ & $2.371,4$ & $1.615,3$ & 940,6 & 937,5 & $5.388,9$ & 500,0 & $4.071,4$ & 495,2 & $12.147,1$ & 629,4 \\
\hline
\end{tabular}

O gênero Psychotria foi comum no estrato regenerativo de todos os ambientes estudados, representado pelos maiores valores de densidade. Este gênero é caracterizado por espécies mais exigentes em condições ambientais, como a menor incidência de luz e maior umidade no solo, compreendendo significativa proporção da vegetação de sub-bosque em muitas florestas tropicais (KINUPP; MAGNUSSON, 2005), sendo que a tendência é o incremento do número de espécies arbóreo-arbustivas no transcorrer da regeneração natural (PESSOA et al., 1997). Essa substituição, segundo Nykvist (1996), ocorre em função das mudanças das condições abióticas, conferindo maior habilidade competitiva às espécies mais exigentes, em detrimento das herbáceas e pioneiras.

A frequência e densidade das espécies do gênero Piper no estrato regenerativo do AT I é mais expressiva quando comparados com esses parâmetros nos outros dois ambientes. Em estudos desenvolvidos por Alvarenga et al. (2006), Piper aduncum se destacou como uma das principais espécies colonizadoras de áreas alteradas nas nascentes estudadas na região sul de Minas Gerais. O gênero Piper é característico por espécies arbustivas, que crescem no interior do sub-bosque ou na orla de trilhas da Floresta Ombrófila 
Densa secundária (BARDELLI et al., 2008), com ampla distribuição em regiões tropicais e temperadas de ambos os hemisférios (GUIMARÃES; GIORDANO, 2004).

\section{CONCLUSÕES}

Os grupos ecológicos de espécies mostraram alterações na participação da composição da vegetação, acompanhando as mudanças de idade destas. Com o avanço das idades, as pioneiras diminuíram enquanto que os demais grupos aumentaram suas participações, fato que pode ser creditado às alterações no ambiente interno da vegetação e que beneficiaram o ingresso e estabelecimento de espécies mais tolerantes à sombra e que apresentam estratégias de regeneração associadas a essa condição.

A conclusão anterior também é amparada pelo fato de que espécies abundantes do estrato arbóreo, especialmente das idades mais avançadas, apresentaram densidades menores no estrato regenerativo, confirmando que mudanças estruturais da vegetação alteraram gradualmente seu ambiente de luz e, consequentemente, o conjunto de espécies regenerantes.

O desenvolvimento do processo sucessional ficou evidenciado também pelas mudanças observadas na densidade, nos dois estratos da vegetação, no período avaliado. A diminuição da densidade no estrato regenerativo e o aumento desta no estrato arbóreo são indicadores de que se intensificaram os efeitos da competição no primeiro caso e de que houve acentuados ingressos e ocupação do espaço no segundo caso.

As espécies Mimosa bimucronata, Myrcia splendens, Cecropia glaziovii, Tibouchina urvilleana e Tibouchina pilosa se destacaram como as principais colonizadoras nas três áreas estudadas, portanto, podem ser indicadas para uso em programas de restauração ecológica em ambientes ciliares com características semelhantes na região do Vale do Itajaí, em Santa Catarina.

\section{REFERÊNCIAS}

ALVARENGA, A. P. et al. Avaliação da regeneração natural na recomposição de matas ciliares em nascentes na região sul de Minas Gerais. Cerne, Lavras, MG, v. 12, n. 4, p. 360-372, 2006.

ANGIOSPERM PHYLOGENY GROUP III. An update of the Angiosperm Phylogeny Group classification for the ordens and families of flowering plants: APG III. Botanical Journal of the Linnean Society, London, v. 161, p. 105-121, 2009.

BARBOSA, L. M. Considerações gerais e modelos de recuperação de formações ciliares. In: RODRIGUES, R. R.; LEITÃO-FILHO, H. F. (Coord.). Matas ciliares: conservação e recuperação. São Paulo: FAPESP, 2000. p. 89-312.

BARDELli, K. C. et al. O gênero Piper L. (Piperaceae) da Mata Atlântica da microbacia do sítio Cabuçu-Proguaru, Guarulhos, SP, Brasil. Hoehnea, São Paulo, v. 35, n. 4, p. 553-561, 2008.

BORÉM, R. A. T.; RAMOS, D. P. Estrutura fitossociológica da comunidade arbórea de uma topossequência pouco alterada de uma área de floresta atlântica, no município de Silva Jardim - RJ. Revista Árvore, Viçosa, MG, v. 25, n. 1, p. 131-140, 2001.

BOTELHO, S. A.; DAVIDE, A. C. Métodos silviculturais para recuperação de nascentes e recomposição de matas ciliares. In: SIMPÓSIO NACIONAL SOBRE RECUPERAÇÃO DE ÁREAS DEGRADADAS, 5., Belo Horizonte. Anais... Belo Horizonte, 2002. p. 123-145.

CAMPOS, J. B.; SOUZA, M. C. Arboreous vegetation of an alluvial riparian forest and their soil relations: Porto Rico Island, Paraná River, Brazil. Brazilian Archives of Biology and Technology, Curitiba, v. 45, n. 2, p. 137-149, 2002.

CARDOSO-LEITE, E. et al. Fitossociologia e caracterização sucessional de um fragmento de mata ciliar, em RioClaro/SP, como subsídio à recuperação da área. Revista do Instituto Florestal, São Paulo, v. 16, n. 1, p. 31-41, 2004.

CARVALHO, F. A. Síndromes de dispersão de espécies arbóreas de florestas ombrófilas submontanas do estado do Rio de Janeiro. Revista Árvore, Viçosa, MG, v. 34, n. 6, p. 1017-1023, 2010.

CHEUNG, K. C. Regeneração natural em áreas de Floresta Atlântica na Reserva Natural Rio Cachoeira, Antonina, PR. 2006. 69 f. Dissertação (Mestre em Ecologia e Conservação) - Universidade Federal do Paraná, Curitiba, 2006. 
COLONETTI, S. et al. Florística e estrutura fitossociológica em floresta ombrófila densa submontana na barragem do rio São Bento, Siderópolis, Estado de Santa Catarina. Acta Scientiarum. Biological Sciences, Maringá, v. 31, n. 4, p. 397-405, 2009.

DURIGAN, G.; SILVEIRA, E. R. Recomposição da mata ciliar em domínio de cerrado, Assis, SP. Scientia Forestalis, Piracicaba, n. 56, p. 135-144, 1999.

EMBRAPA. Levantamento de reconhecimento dos solos do Estado de Santa Catarina. Boletim de Pesquisa, Colombo, PR, n. 6, 1998.

DURIGAN, G.. Solos do Estado de Santa Catarina. Boletim de Pesquisa e Desenvolvimento, Colombo, PR, n. 46, 2004.

EMPRESA DE PESQUISA AGROPECUÁRIA E EXTENSÃO RURAL DE SANTA CATARINA. Atlas Climatológico do Estado de Santa Catarina. Florianópolis. 2002. 1 CD.

FERREIRA, D. A. C.; DIAS, H. C. T. Situação atual da mata ciliar do Ribeirão São Bartolomeu em Viçosa, MG. Revista Árvore, Viçosa, MG, v. 28, n. 4, p. 617-623, 2004.

GUIMARÃES, E. F.; GIORDANO, L. C. S. Piperaceae no nordeste brasileiro I: Estado do Ceará. Rodriguésia, Rio de Janeiro, v. 55, p. 21-46, 2004.

HOWE, H. F.; SMALLWOOD, J. Ecology of seed dispersal. Annual Review of Ecology and Systematics, Palo Alto, v. 13, p. 201-228, 1982.

IBARRA-MANRÍQUEZ, G. et al. Fenologia de lianas y arboles anemocoros en una Selva Calido-Humeda de México. Biotropica, Washington, v. 23, p. 242-254, 1991.

IBGE. Manual técnico da vegetação brasileira. Rio de Janeiro: IBGE, 2012. 271 p.

KINUPP, V. F.; MAGNUSSON, W. E. Spatial patterns in the understory shrub genus Psychotria in central Amazonia: effects of distance and topography. Journal of Tropical Ecology, Cambridge, v. 21, p. 368-374, 2005.

KLEIN, R. M. Ecologia da flora e vegetação do Vale do Itajaí. Sellowia, Itajaí, v. 1, n. 32, p. 165-389, 1980. LINGNER, D. V. et al. Fitossociologia do componente arbóreo/arbustivo da Floresta Ombrófila Densa em Santa Catarina. In: VIBRANS, A. C. et al. (Ed.). Inventário Florístico Florestal de Santa Catarina, Vol. IV, Floresta Ombrófila Densa. Blumenau: Edifurb, 2013. p. 159-200.

MAGURRAN, A. E. Measuring biological diversity. Oxford: Blackwell Science, 2004.

MANTOVANI, M. et al. Diversidade de espécies e estrutura sucessional de uma formação secundária da floresta ombrófila densa. Scientia Forestalis, Piracicaba, n. 67, p. 14-26, 2005.

MEYER, L. et al. Regeneração natural da Floresta Ombrófila Densa em Santa Catarina. In: VIBRANS, A. C. et al. (Ed.). Inventário Florístico Florestal de Santa Catarina, Vol. IV, Floresta Ombrófila Densa. Blumenau: Edifurb, 2013. p. 201-256.

MORELLATO, L. P. C. et al. Estudo comparativo da fenologia de espécies arbóreas de floresta de altitude e floresta mesófila semidecídua na Serra do Japi, Jundiaí, São Paulo. Revista Brasileira de Botânica, São Paulo, v. 12, p. 85-98, 1989.

MORELLATO, L. P. C. et al. Phenology of Atlantic rain forest trees: a comparative study. Biotropica, Washington, v. 32, n. 4b, p. 811-823, 2000.

MUELLER-DOMBOIS, D.; ELLENBERG, H. Aims and methods of vegetation ecology. New Jersey: The Blackburn Press, 2002. 547 p.

NAPPO, M. E. et al. Reflorestamentos mistos com essências nativas para recomposição de matas ciliares.

Boletim Agropecuário da Universidade Federal de Lavras, Lavras, MG, v. 30, p. 1-31, 1999.

NAPPO, M. E. et al. Dinâmica da estrutura fitossociológica da regeneração natural em sub-bosque de Mimosa scabrella Bentham em área minerada, em Poços de Caldas, MG. Revista Árvore, Viçosa, MG, v. 28, n. 6, p. 811-829, 2004.

NEBEL, G. et al. Structure and floristic composition of flood plain forests in the Peruvian Amazon I. Overstorey. Forest Ecology and Management, Amsterdam, v. 150, p. 27-57, 2001.

NEGRELLE, R. R. B. The Atlantic forest in the Volta Velha Reserve: a tropical rain forest site soutside the tropics. Biodiversity and Conservation, London, v. 11, p. 887-919, 2002.

NÓBREGA, A. M. F. et al. Regeneração natural em remanescentes florestais e áreas reflorestadas da várzea do Rio Mogi-Guaçu, Luiz Antônio - SP. Revista Árvore, Viçosa, MG, v. 32, n. 5, p. 909-920, 2008.

NYKVIST, N. Regrowth of secundary vegetation ofter the "Borneo fire" of 1982-1983. Journal of Tropical

Ci. Fl., v. 27, n. 1, jan.-mar., 2017 
Ecology, Cambridge, v. 12, p. 307-312, 1996.

OLIVEIRA-FILHO, A. T. Estudos ecológicos da vegetação como subsídios para programas de revegetação com espécies nativas: uma proposta metodológica. Cerne, Lavras, MG, v. 1, n. 1, p. 64-72, 1994a.

OLIVEIRA-FILHO, A. T. et al. Estrutura fitossociológica e variáveis ambientais em um trecho da mata ciliar do córrego dos Vilas Boas, Reserva Biológica do Poço Bonito, Lavras (MG). Revista Brasileira de Botânica, São Paulo, v. 17, n. 1, p. 67-85, 1994b.

OLIVEIRA-FILHO, A. T.; FONTES, M. A. L. Patterns of floristic differentiation among Atlantic Forest in southeastern Brazil and the influence of climate. Biotropica, Washington, v. 32, n. 4b, p. 793-810, 2000.

PESSOA, S. V. A. et al. Composição florística e estrutura do componente arbustivo-arbóreo de um trecho secundário de floresta montana na Reserva Ecológica de Macaé de Cima. In: JARDIM BOTÂNICO (Rio de Janeiro, RJ) Serra de Macaé de Cima: diversidade florística e conservação da Mata Atlântica. Rio de Janeiro: Jardim Botânico, 1997. p.147-168.

PIJL, L. V. D. Principles of dispersal in higher plants. 3. ed. New York: Springer-Verlag, 1982.

REITZ, P. R. et al. Madeiras do Brasil. Florianópolis: Lunardelli, 1979. 320 p.

RODRIGUES, R. R.; GANDOLFI, S. Conceitos, tendências e ações para a recuperação de florestas ciliares. In: RODRIGUES, R. R.; LEITÃO-FILHO, H. F. (Coord.). Matas ciliares: conservação e recuperação. São Paulo: FAPESP, 2000. p. 241-243.

SCARIOT, E. C.; REIS, A. Riqueza e estrutura florística de corredores ciliares em regeneração natural no planalto norte catarinense, sul do Brasil. Perspectiva, Florianópolis, v. 34, n. 125, p. 53-65, 2010.

SEITZ, R. A. A regeneração natural na recuperação de áreas degradadas. In: SIMPÓSIO SULAMERICANO; SIMPÓSIO NACIONAL - RECUPERAÇÃO DE ÁREAS DEGRADADAS, 1., Foz do Iguaçu. Anais... Foz do Iguaçu: FUPEF, 1994. p. 103-110.

SEVEGNANI, L. Vegetação da Bacia do Rio Itajaí em Santa Catarina. In: SCHÄFFER, W. B.; PROCHNOW, M. (orgs.). A Mata Atlântica e você. [s. 1.]: APREMAVI, 2002. p.85-101.

SIMINSKI, A. et al. Sucessão florestal secundária no município de São Pedro de Alcântara, litoral de Santa Catarina: estrutura e diversidade. Ciência Florestal, Santa Maria, v. 14, n. 1, p. 21-33, 2004.

TABARELLI, M.; MANTOVANI, W. A regeneração de uma floresta tropical montana após corte e queima (São Paulo-Brasil). Revista Brasileira de Biologia, São Carlos, v. 59, n. 2, p. 239-250, 1999.

VENZKE, T. S.; MARTINS, S. V. Aspectos florísticos de três estágios sucessionais em mata ciliar em Arroio do Padre, extremo sul do Brasil. Floresta, Curitiba, v. 43, n. 2, p. 191-204, abr./ jun. 2013. 